\title{
Correction to: Chronic traumatic encephalopathy in two former Australian National Rugby League players
}

\author{
Michael E. Buckland ${ }^{1,2^{*}}$, Joanne Sy ${ }^{1}$, Istvan Szentmariay ${ }^{3}$, Alexandra Kullen ${ }^{3}$, Maggie Lee ${ }^{1}$, Antony Harding ${ }^{1}$, \\ Glenda Halliday ${ }^{4}$ and Catherine M. Suter ${ }^{1,5}$
}

\section{Correction to: Acta neuropathol commun (2019) 7: 97. https://doi.org/10.1186/s40478-019-0751-1}

In the original publication of this article [1] the term 'National Rugby League (NRL)' was used to refer to professional rugby league competition sport in Australia. The term should have read 'professional rugby league' to include the various professional competition nomenclatures over the last fifty years, including but not limited to NRL. In this correction article, the incorrect and correct information are published.

Due to these changes the term 'NRL' should be disregarded from the abbreviation list.

Incorrect
Chronic traumatic encephalopathy
in two former Australian National
Rugby League players
Here we report the finding of CTE
pathology in the brains of two
former Australian National Rugby
League (NRL) players.

Both cases were middle-aged exprofessionals who had each played more than 150 first grade $\mathbf{N R L}$ games over many years.

There is little available data on long-term neurological outcomes in rugby league players, however a recent assessment of 25 retired NRL players identified significant motor and cognitive changes, along with neurophysiological

\section{Corrected information}

Chronic traumatic encephalopathy

in two former Australian professional rugby league players

Here we report the finding of CTE pathology in the brains of two former Australian professional rugby league players.

Both cases were middle-aged exprofessionals who had each played more than 150 first grade professional rugby league games over many years.

There is little available data on long-term neurological outcomes in rugby league players, however a recent assessment of 25 retired professional rugby league players identified significant motor and cognitive changes, along with

\begin{tabular}{ll}
\multicolumn{1}{c}{ (Continued) } & \\
\hline Incorrect & Corrected information \\
\hline $\begin{array}{l}\text { alterations compared with } \\
\text { matched controls with no history } \\
\text { of contact sports [13]. }\end{array}$ & $\begin{array}{l}\text { neurophysiological alterations com- } \\
\text { pared with matched controls with } \\
\text { no history of contact sports [13]. }\end{array}$ \\
$\begin{array}{ll}\text { Table 1. Summary of } & \text { Table 1. Summary of } \\
\text { neuropathogical features of brains } & \text { neuropathogical features of brains } \\
\text { of two former NRL players } & \begin{array}{l}\text { of two former professional rugby } \\
\text { league players }\end{array}\end{array}$
\end{tabular}

Author details

'Department of Neuropathology, Royal Prince Alfred Hospital, 94 Mallet St, Camperdown, NSW 2050, Australia. ${ }^{2}$ Discipline of Pathology, School of Medical Sciences, Brain \& Mind Centre, University of Sydney, Camperdown, NSW 2006, Australia. ${ }^{3}$ Forensic and Analytical Science Service, Lidcombe, NSW 2141, Australia. ${ }^{4}$ Central Clinical School, Brain \& Mind Centre, University of Sydney, Camperdown, NSW 2006, Australia. ${ }^{5}$ Faculty of Medicine, University of New South Wales, Kensington, NSW 2052, Australia.

Published online: 29 July 2019

\section{Reference}

1. Buckland ME, Sy J, Szentmariay I et al (2019) Chronic traumatic encephalopathy in two former Australian National Rugby League players. Acta Neuropathol Commun 7:97. https://doi.org/10.1186/s40478-019-0751-1

*Correspondence: michael.buckland@sydney.edu.au

'Department of Neuropathology, Royal Prince Alfred Hospital, 94 Mallet St, Camperdown, NSW 2050, Australia

2Discipline of Pathology, School of Medical Sciences, Brain \& Mind Centre,

University of Sydney, Camperdown, NSW 2006, Australia

Full list of author information is available at the end of the article

(c) The Author(s). 2019 Open Access This article is distributed under the terms of the Creative Commons Attribution 4.0 International License (http://creativecommons.org/licenses/by/4.0/), which permits unrestricted use, distribution, and reproduction in any medium, provided you give appropriate credit to the original author(s) and the source, provide a link to the Creative Commons license, and indicate if changes were made. The Creative Commons Public Domain Dedication waiver (http://creativecommons.org/publicdomain/zero/1.0/) applies to the data made available in this article, unless otherwise stated. 